Running head: Changes in Mastery and Self-efficacy During a Quit Attempt

\title{
Day-to-day mastery and self-efficacy changes during a smoking quit attempt:
}

\section{Two studies}

Lisa M. Warner ${ }^{1,2}$, Gertraud Stadler ${ }^{3}$, Janina Lüscher ${ }^{4}$, Nina Knoll ${ }^{1}$, Sibylle Ochsner ${ }^{4}$, Rainer Hornung ${ }^{4}$, Urte Scholz ${ }^{4}$

\author{
${ }^{1}$ Freie Universität Berlin, Germany \\ ${ }^{2}$ MSB Medical School Berlin, Germany \\ ${ }^{3}$ University of Aberdeen, United Kingdom \\ ${ }^{4}$ University of Zurich, Switzerland
}

Word count (exc. figures/tables): 5050

*Requests for reprints should be addressed to Prof. Dr. Urte Scholz

Postal address: University of Zurich, Binzmühlestrasse 14 Box 14, CH-8050 Zürich, Switzerland

Email: urte.scholz@psychologie.uzh.ch 


\begin{abstract}
Objective: In social-cognitive theory it is hypothesized that mastery experiences (successfully implementing behaviour change) are a source of self-efficacy, and self-efficacy increases the opportunity for experiencing mastery. Vicarious experiences (seeing others succeed) are suggested as another source of self-efficacy. However, the hypothesis of this reciprocal relationship has not been tested using a day-to-day design.

Design: This article reports findings from two intensive longitudinal studies, testing the reciprocal relationship of self-efficacy and its two main sources within the naturally occurring process of quitting smoking (without intervention). Smokers (Study 1: $N=100$ smokers in smoker-non-smoker couples (1787 observations); Study 2; $N=81$ female (1401 observations) and $N=79$ male smokers (1328 observations) in dual-smoker couples) reported their mastery experiences (not smoking the entire day; in Study 2, mastery experience of partner served as vicarious experience) and smoking-specific self-efficacy for 21 days after a self-set quit date.
\end{abstract}

Methods: Time-lagged multilevel analyses were conducted using change-predicting-change models.

Results: Increases in mastery experiences predicted changes in self-efficacy, and increases in self-efficacy predicted changes in mastery experiences in Study 1. Study 2 replicated these results and showed contagion effects (partners' mastery on individuals' mastery, and partners' self-efficacy on individuals' self-efficacy), but found no evidence for a link between vicarious experiences (partners' mastery experiences) and individuals' self-efficacy.

Conclusions: This article demonstrates that mastery experiences and self-efficacy show a reciprocal relationship within smokers during a quit attempt in a day-to-day design, as well as contagion effects in couples when both partners try to quit simultaneously.

Keywords: social-cognitive theory, sources of self-efficacy, couples, daily diary, ecological momentary assessment, intensive longitudinal 
Smoking is responsible for about 6 million deaths worldwide yearly (World Health Organization, 2011). Although the fatal impact of smoking is well known and quitting smoking is associated with immediate positive consequences for health, $25 \%$ of the Swiss population between the ages of 14-65 smoke (Gmel, Kuendig, Notari, \& Gmel, 2015). Although more than half $(56.7 \%)$ intend to quit, only around 3-5\% achieve long term abstinence (Gmel, Kuendig, Notari, Gmel, \& Flury, 2013). Findings on the typical smoking cessation process show that most relapses occur within one week after the quit date (Hughes, Keely, \& Naud, 2004). Thus, research into the rapid changes in smokers' cognitions within the early days of a quit attempt is necessary to develop intervention strategies for more sustaining smoking cessation programs.

\section{The role of self-efficacy in quitting smoking}

A powerful cognition enabling health behaviour changes is self-efficacy (Bandura, 1997; Luszczynska \& Schwarzer, 2015), which refers to the belief in being able to reach a goal by one's own means. People with stronger self-efficacy - regardless of whether this belief represents their actual capabilities - set more ambitious goals for themselves and invest more effort into their pursuit (Bandura, 1997). Consequently, if smokers do not believe in being able to quit, chances are lower that they even try. In research on smoking, self-efficacy beliefs were identified as one key psychological factor for the initiation of a smoking quit attempt, the reduction in number of cigarettes smoked daily, the success of quit attempts and long-term abstinence after smoking cessation programs (Baldwin et al., 2006; DiClemente, Fairhurst, \& Piotrowski, 1995; Dijkstra \& Vries, 2000; Gwaltney, Metrik, Kahler, \& Shiffman, 2009). Despite evidence on the association between self-efficacy and smoking cessation, there is only little research on the origins and the development of individual's selfefficacy beliefs during the smoking cessation process (neither for other health behaviours; Dijkstra \& Vries, 2000; French, Olander, Chisholm, \& Mc Sharry, 2014; Warner et al., 2014). 


\section{Mastery experiences and self-efficacy}

Self-efficacy is proposed to have four sources: mastery experiences, vicarious experiences, verbal persuasion, and somatic and affective states (Bandura, 1997). Mastery experiences are assumed to be the strongest source of self-efficacy. If individuals succeed in changing their health behaviour - such as being abstinent from smoking for an entire day they experience mastery and this strengthens their self-efficacy (Garcia, Schmitz, \& Doerfler, 1990; Kirchner, Shiffman, \& Wileyto, 2012). Higher self-efficacy in turn should make individuals try more often and harder, which should create more opportunities to successfully perform new health behaviours and to experience mastery, initiating a reciprocal relationship, also called an upward spiral. French (French, 2013, p. 283) points out that "self-efficacy is proposed to be both a cause and an effect of performing a behaviour" and he concludes that "there is a need for careful attention to temporal aspects of attempts to test this theory". The vast majority of research on positive associations between self-efficacy and health behaviours is, however, deduced from between-person analyses (Shiffman et al., 2000; Van Zundert, Engels, \& Kuntsche, 2011). Additionally, such prospective smoking cessation studies are usually characterized by long-term intervals between assessment points (Westmaas, Bontemps-Jones, \& Bauer, 2010) and therefore reveal only little about the short-lived dynamic processes between mastery experiences and self-efficacy during a quit attempt. Gwaltney and colleagues (Gwaltney et al., 2009, p. 56) conclude in their meta-analysis on the relation between self-efficacy and smoking that "Although SE [self-efficacy] has a reliable association with future abstinence, it is less robust than expected". The question of how mastery experience and self-efficacy mutually affect one another, therefore calls for an analysis of daily within-person changes (Shiffman et al., 2000).

\section{Vicarious experience and self-efficacy}

Next to mastery experiences, vicarious experiences are proposed to be the second most influential source of self-efficacy in social cognitive theory (Bandura, 1997; Maddux, 
2002). Vicarious experiences develop when other persons (role models), who successfully change their behaviour, can be observed. Accordingly, previous literature on smokers' quit attempts confirms that seeing others smoke is related to lower self-efficacy (Gwaltney, Shiffman, \& Sayette, 2005; Van Zundert et al., 2011) and to a higher risk of relapse (Gwaltney, Bartolomei, Colby, \& Kahler, 2008). However, whether observing others successfully initiating smoking cessation is associated with an observer's own self-efficacy and abstinence has not been thoroughly investigated. In a large population-based survey (3722 participating married and cohabiting couples) on the comparison of the effect of having a partner who takes up a health behaviour (e.g., quits smoking) to having a partner whose behaviour is consistently healthy (e.g., never smokes), the importance of positive role models in the quitting process was implied (Jackson, Steptoe, \& Wardle, 2015). Authors found that if one partner in an intimate relationship quits smoking this significantly increases the chances that the other partner will do so as well. The effects of a quitting partner were also stronger than having a constantly non-smoking partner within a 2-year study period. This may suggest that recent vicarious experiences from a role model have a stronger effect on quitting smoking than dated vicarious experiences from a partner who quit long ago or observing a partner, who never started smoking, so never served as a role model to quit (Roberts, Dale, Dorey, Bullen, \& Maddison, 2016). However, the study by Jackson and colleagues did not test for the psychological mechanisms explaining this social contagion effect between intimate partners and their health behaviours. Such contagion effects are usually defined as "spread of affect, attitude or behaviour from Person A ("the initiator") to Person B ("the recipient") where the recipient does not perceive an intentional influence attempt on the part of the initiator." (Levy \& Nail, 1993). Based on SCT, it can be assumed that changes in complex health behaviours such as smoking are not just unconsciously imitated by people close to us. But that conscious processes such as self-efficacy might be an additional working 
mechanism, which is strengthened by vicarious experiences. It is only then that behavioural changes result.

Summarizing the limited research on mastery experiences and vicarious experience within the smoking cessation process, one can conclude that experiencing mastery should help boosting self-efficacy beliefs, which in turn increase opportunities for more mastery. This intra-individual process might, however, not be enough to quit for good. Additionally, smokers might benefit from recent observations of a person close to them in a similar situation who successfully maintains abstinence. This effect could either be direct behavioural contagion (unintended imitation) or based on changes in self-efficacy. Effects of contagion and vicarious experiences should best be observable in dual-smoker couples intending to quit.

\section{Aims of Study 1 and Study 2}

The aim of Study 1 (smokers with a non-smoking partner) was to examine whether mastery experiences and self-efficacy are reciprocally related, or whether one of them is more likely to precede the other. To investigate such time-lagged effects, Study 1 was designed as an intra-individual intensive longitudinal study, allowing to relate changes in both constructs from the day before yesterday to yesterday (prior time-lagged changes) to changes from yesterday to today (concurrent same-day changes) and vice versa.

The first aim of Study 2 (dual-smoker couples) was to replicate these intra-individual associations of changes in mastery experiences and self-efficacy. In Study 2 another aim was to analyse between-partner effects over time: In particular, an effect of vicarious experiences was hypothesized in that one partner's mastery experiences would affect the other individuals' self-efficacy (concurrent as well as prior changes) and vice versa.

\section{Method}

\section{Participants}


Study 1 was part of a larger project [project name blinded for review] funded by the [funding agency blinded for review]. Inclusion criteria: participants had to be in a committed relationship (i.e., either married or in a stable heterosexual relationship for at least one year) with a non-smoking partner, who also participated in the study, living together for at least six months, being regular smokers as according to the WHO (at least one cigarette per day; World Health Organization, 1998) and having the intention of quitting smoking during the study period. Exclusion criteria: participating in a professional smoking cessation programme, being pregnant, in shift work, or not fluent in German. All ethical standards of the 2000 Helsinki declaration were met.

Study 2 was part of a larger project [project name blinded for review] funded by the [funding agency blinded for review]. Ethical approval was granted by the Ethics Committee of the [name of committee and ethical approval number blinded for review]. Additional inclusion criteria: couples with both partners being regular smokers as per the definition of the WHO (World Health Organization, 1998), agreeing on a joint self-set quit date within the study period. Otherwise, Study 2 had the same recruitment strategy, inclusion and exclusion criteria as Study 1. For more details about recruitment and study procedure, please see for Study 1 [blinded for review] and for Study 2 [blinded for review].

In both studies, couples received up to 200 Swiss Francs (approximately 207 USD) as compensation.

\section{Design}

Studies 1 and 2 were conducted with the same intensive longitudinal study design providing neither psychological intervention nor nicotine replacement therapy. Study 1 was conducted from 2009 to 2013, Study 2 was conducted from 2011 to 2014 . Initially, participants were screened for study eligibility with an online questionnaire (Study 1: $N=907$ couples screened, $n=306$ couples ineligible; Study 2: $N=220$ screened, $n=77$ ineligible). Eligible participants received information about the study and gave informed consent before 
answering a baseline questionnaire on social-cognitive variables, smoking behaviour and socio-demographics at the research institute. Participants committed to a self-set quit date within the following 25 days (joint date for couples in Study 2). Both partners in each couple received a study smartphone and were instructed to complete daily diaries starting 10 days before the self-set quit date on Day 11 and continuing for 21 days thereafter. Software to answer the questionnaires was developed by www.mquestsys.com and preinstalled on the devices. In the diary, participants answered questions on positive and negative affect, constructs of the Health Action Process Approach (Schwarzer, 2008) and social exchange processes (i.e., social support, social control, companionship). Participants needed a maximum of 10 minutes per day to complete the diary. Participants were asked to complete questionnaires independently from each other each night within one hour before going to bed. If they did not respond for three consecutive nights (the devices did not prompt them), they were contacted via phone to increase study compliance. As mastery experience of quitting smoking only occurs after the quit date, all analyses focus on 21 days following the quit date. Participants showed high diary completion rates (Study 1: $n=1787$ [89.4\%] of 2000 (20 days * 100 smokers) possible observations; Study 2: $n=1401$ [84.4\%] for female smokers, $n=$ 1328 for male smokers [80.0\%] out of 1660 (20 days * 83 smokers) possible diary day observations). Participants were free to use any form of nicotine replacement therapy, but were not provided any, nor did they use it often (average use $8.2 \%$ days Study $1 ; 7.8 \%$ days Study 2). After the diary assessment, couples returned to the laboratory for the one-month follow-up and completed biochemical verification of smoking status with a carbon monoxide test of expired air (West, Hajek, Stead, \&Stapleton, 2005). They were further asked to fill in follow-up questionnaires at 1 and 6 months after self-set quit date.

\section{Measures}

Study 1 and Study 2 assessed the same items with the same response categories by means of the same electronic devices. For Study 2 items were the same for both partners. 
Mastery experiences. To assess whether participants had experienced mastery on a given day, they answered the item "Did you smoke today (including only one puff)?" every evening before going to bed. The answer "no" (1) was rated as having experienced mastery. The answer "yes" (0) indicated that participants had no mastery experience on that day.

Smoking-specific self-efficacy. To assess smoking-specific self-efficacy on a daily basis one item from a previously validated scale was chosen (Scholz, Nagy, Gohner, Luszczynska, \& Kliegel, 2009). Participants rated the item "I am confident that I can refrain from smoking tomorrow even if it is difficult” on a scale from ,not at all true” (1) to „,completely true” (6).

\section{Data Analysis}

Change-predicting-change analyses were implemented as multilevel models in SPSS 24 (Stadler, Snyder, Horn, Shrout, \& Bolger, 2012). Two change scores were calculated for each measure and each study: Concurrent change was calculated by subtracting the variable's raw score yesterday from the variable's raw score today (Mastery $t_{t}$ - Mastery M $_{t-1}$, Self-efficacy $t$ - Self-efficacy ${ }_{t-1}$ ). Prior change reflects the change from two days ago to yesterday (raw score yesterday minus raw score for the day before yesterday: Mastery $t_{t-1}$ - Mastery $\mathrm{t}_{t-2}$; Selfefficacy $_{t-1}$ - Self-efficacy $y_{t-2}$ ). This procedure results in zero if no change occurred, positive change scores for increases and negative change scores for decreases in mastery experiences and self-efficacy (change scores for mastery experiences could range from - 1 to 1 , change scores for self-efficacy from -5 to 5). Days 13-32 were analysed in both studies, as mastery experiences can only occur from the quit date on Day 11 on, and because prior changes could only be calculated for Day 13 onwards (there is no prior change to Day 11 and Day 12), all models included a linear time variable starting on Day 13 (coded as 0) and counting 0-19 (study Days 13-31). As this change-predicting-change approach eliminates between-person differences, no random effect for the intercept can be estimated (for further explanation of 
change-predicting-change generalized linear models see Allison, 2005; Scholz et al., 2016; Stadler et al., 2012).

In each model, the dependent variable was the respective concurrent change score (i.e., mastery experiences or self-efficacy), adjusted for its own prior change score. In addition, prior and concurrent change of the respective independent variable were included in the models to test for lagged and concurrent effects. If concurrent change in the respective independent variable predicted concurrent change in the respective dependent variable, then the processes were assumed to work in parallel. If prior change in the respective independent variable predicted concurrent change in the respective dependent variable after adjusting for concurrent change of the independent variable, this means that prior changes (from 2 days ago to yesterday) in the respective independent variable were associated with later changes (from yesterday to today) in the respective dependent variable, over and above same-day changes. Lagged effects indicate a temporal association, one prerequisite for causality (albeit no final test, see also Stadler et al., 2012). To test for the effects of vicarious experiences, Study 2 further included prior and concurrent changes in the respective independent change scores reported by partners in addition to the respective independent change scores reported by the individuals.

\section{Results}

\section{Descriptive Results}

In Study $1, N=100$ smokers were included in the analyses. They were on average $M$ $=40.48$ years old $(S D=9.86$, range $=19-72)$. The majority were male $(72 \%)$, had children (58\%), and had attended at least 9 years of schooling (70\%). All were either married (66\%) or in a committed relationship (34\%). Participants reported to have experienced mastery in about half of the observations $(M=0.51, S D=0.50$, range $=0-1)$ and rated their self-efficacy above the mid-point of the scale, $(M=4.63, S D=1.39$, range $=1-6)$. 
In Study 2, $n=85$ partners of each gender within dual-smoker couples were included in the study. Data of $n=81$ women and $n=79$ men could be included in the analyses (two couples provided data before the quit date only, in addition, data of one woman and three men could not be analysed, as they did not provide sufficient sets of three consecutive days of data after the quit date to compute all changes scores). Women were on average $M=38.5$ $(S D=14.64$, range 19-68) and men $M=40.7(S D=14.51$, range 20-71) years old. About half of the sample was married $(44.7 \%)$, reported having attended 9 years of schooling (women: 63.5\%; men: $76.5 \%$ ), and $28.2 \%$ had children. Participants again reported mastery experience on half of the days (female smokers: $M=0.53, S D=0.50$; male smokers: $M=0.48, S D=$ 0.50 ; range $=0-1)$ and rated their self-efficacy above the mid-point of the scale (female smokers: $M=4.62, S D=1.44$; male smokers: $M=4.59, S D=1.45$; range $=1-6$ ).

For Study 1, 34 (34.0\%) participants and for Study 2, 28 (32.9\%) men and 34 (40.0\%) women reported continuous abstinence at the one-month follow-up assessment. All participants, who self-reported continuous abstinence were also biochemically identified as non-smokers in both studies at this follow-up. Being biochemically abstinent was correlated with aggregated self-efficacy (Study 1: $r=.48, p<.001$, Study 2: $r=.56, p<.001$ for women, $r=.49, p<.001$ for men) and with aggregated mastery experiences (Study 1: $r=.59$, $p<.001$, Study 2: $r=.49, p<.001$ in women, $r=.64, p<.001$ in men) at the between level across the diary period.

\section{Results Study 1}

Tables 1 and 2 show the effects for all tested change-predicting-change multilevel models conducted for Studies 1 and 2.

In Study 1 prior $(b=0.17,95 \%$ CI [0.06; 0.27], $p<.01)$ and concurrent changes in mastery experiences $(b=0.36,95 \% \mathrm{CI}[0.20 ; 0.52], p<.001)$ were found to relate to concurrent changes in self-efficacy (after controlling for prior changes in self-efficacy; see Table 1). Vice versa, prior changes $(b=0.06,95 \%$ CI $[0.03 ; 0.09], p<.001)$ and concurrent 
changes in self-efficacy $(b=0.07,95 \% \mathrm{CI}[0.04 ; 0.11], p<.001)$ were associated with concurrent changes in mastery experiences as well (after adjusting for prior changes in mastery experiences, see Table 2). As changes in mastery experiences predicted changes in self-efficacy, and changes in self-efficacy predicted changes in mastery experiences over time, the study's findings support the hypothesized upward spiral between mastery experiences and self-efficacy on a day-to-day basis after a self-set quit date.

Table 1 about here

\section{Results Study 2}

Replication of the mutual effects of mastery experiences and self-efficacy. The prediction of concurrent changes in self-efficacy by prior and concurrent changes in mastery experiences only partially replicated Study 1: Individuals' own concurrent changes in mastery experiences $\left(b_{\text {women }}=0.31,95 \%\right.$ CI $[0.17,0.45], p<.001 ; b_{\text {men }}=0.21,95 \%$ CI $[0.04$, $0.39], p<.05)$ but not their own prior changes in mastery experiences $\left(b_{\text {women }}=0.18,95 \% \mathrm{CI}\right.$ $[-0.01,0.37], p>.05, b_{m e n}=0.15,95 \%$ CI $\left.[-0.08,0.37], p>.05\right)$ had an effect on concurrent changes in self-efficacy, both for women and men (after adjusting for prior changes in selfefficacy, see Table 1). Hence, Study 2 confirms that changes in mastery experiences and selfefficacy occur on a same-day basis, but changes in mastery experience did not precede changes in self-efficacy, neither in men nor in women. The prediction of concurrent changes in mastery experiences by prior and concurrent changes in self-efficacy replicated Study 1:

For both men and women, concurrent changes in mastery experiences were predicted by prior $\left(b_{\text {women }}=0.03,95 \%\right.$ CI $[0.01,0.05], p<.01 ; b_{\text {men }}=0.03,95 \%$ CI $\left.[0.001,0.05], p<.05\right)$ as well as concurrent changes in self-efficacy $\left(b_{\text {women }}=0.03,95 \%\right.$ CI $[0.01,0.05], p<.01 ; b_{m e n}$ $=0.04,95 \% \mathrm{CI}[0.01,0.07], p<.05 ;$ after controlling for prior changes in mastery experiences, see Table 2). 
Table 2 about here

\section{Testing effects of contagion and vicarious experiences between partners. The} prediction of concurrent changes in self-efficacy yielded similar result patterns for men and women: Over and above individuals' own prior changes in self-efficacy, and their own prior and concurrent changes in mastery experiences (which were all significant predictors in contrast to the first models in Study 2, in which prior changes in mastery experiences were not significant, see Table 1) partners' prior $\left(b_{\text {women's partners }}=0.12,95 \%\right.$ CI $[0.07,0.16], p<$ $\left..001 ; b_{\text {men's partners }}=0.14,95 \% \mathrm{CI}[0.07,0.20], p<.001\right)$ and partners' concurrent changes in self-efficacy $\left(b_{\text {women's partners }}=0.11,95 \%\right.$ CI $[0.06,0.15], p<.001 ; b_{\text {men's partners }}=0.14,95 \% \mathrm{CI}$ $[0.08,0.21], p<.001)-$ but not partners' prior $\left(b_{\text {women's partners }}=0.02,95 \%\right.$ CI $[-0.13,0.17], p$ $\left.>.05 ; b_{\text {men's partners }}=-0.16,95 \% \mathrm{CI}[-0.37,0.06], p>.05\right)$ and partners' concurrent changes in mastery experiences $\left(b_{\text {women's partners }}=0.11,95 \%\right.$ CI $[-0.06,0.28], p>.05 ; b_{\text {men's partners }}=-0.09$, 95\% CI [-0.30, 0.12], $p>.05)$ - predicted individuals' self-efficacy.

Predicting concurrent changes in mastery experiences yielded slightly different results for men and women. For women, own prior $\left(b_{\text {women }}=0.03,95 \%\right.$ CI $[0.003,0.06], p<$ $.05)$ and concurrent changes in self-efficacy $\left(b_{\text {women }}=0.04,95 \% \mathrm{CI}[0.01,0.08], p<.05\right)$ predicted their concurrent changes in mastery experiences (after adjusting for their own prior changes in mastery experiences, see Table 2). Over and above these individual effects, women's partners' concurrent changes in mastery experiences also affected women's changes in mastery experiences $\left(b_{\text {women's partners }}=0.20,95 \% \mathrm{CI}[0.08,0.32], p<.01\right)$, but women's partners' changes in self-efficacy did not (see Table 2). Men's concurrent changes in mastery experiences were predicted by their partner's concurrent changes in mastery experiences $\left(b_{\text {men's partners }}=0.28,95 \% \mathrm{CI}[0.12,0.43], p<.01\right)$, but not by their own changes in selfefficacy, nor by their partner's changes in self-efficacy (see Table 2). 
To summarize, partner effects only emerged in the direction of changes in partner's self-efficacy to individuals' self-efficacy and from partner's mastery experiences to individuals' mastery experiences pointing to a contagion effect. There were no effects from partner's changes in self-efficacy to the other partner's changes in mastery experience, nor from partner's changes in mastery experiences to the other partner's changes in self-efficacy. Hence, no effects of vicarious experiences from observing the partner for one's own selfefficacy were found.

\section{Discussion}

In social-cognitive theory (Bandura, 1997) it is proposed that self-efficacy beliefs are built upon two major sources - mastery and vicarious experiences. In two intensive longitudinal studies on smokers, two research questions were investigated. The first research question as to whether there is an upward spiral between mastery experiences and selfefficacy on an intra-individual level could be confirmed. In Study 1, concurrent and prior changes of both constructs related to changes in both constructs over time. In Study 2, selfefficacy changes co-occurred and preceded changes in mastery experiences, however, changes in mastery experiences did not precede changes in self-efficacy, but only cooccurred.

The second hypothesis that self-efficacy is also inter-individually affected by vicarious experiences in intimate partners, who try to quit smoking together, could not be confirmed. Partners' changes in mastery experiences did not elicit changes in self-efficacy for either men or women. Results of Study 2 rather indicate a contagion effect as partners in dual smoking couples seemed to adapt their self-efficacy levels to one another, both simultaneously as well as with a lagged effect.

Both studies supported the assumption that mastery experiences and self-efficacy are mutually dependent, but also highlight that their predictive order may be hard to establish (French, 2013). Findings contradict social-cognitive theory to some extent, as Bandura 
postulated that "Successes build a robust belief in one's personal efficacy" (Bandura, 1995, p3). The current findings, however, indicate that effects of mastery experiences on selfefficacy are less robust than expected during the acute process of withstanding an addiction. This highlights the importance of an analysis of day-to-day changes of social-cognitive variables within individuals during the behaviour change process that is characterised by considerable variability (Garcia et al., 1990).

One explanation for a lack of vicarious-experience effects might be that all models in Study 2 adjusted for individuals' own mastery experiences, which are assumed to be the most prominent source of self-efficacy. Vicarious experiences are, however, assumed to take a more important role, if mastery experience is not (yet) existent (Palmer, 2006). As around $65 \%$ ( $n=52$ women, $n=54$ men) of the sample reported to have experienced at least one day of mastery during the study period, the effects of individuals' own mastery experiences might have outweighed effects of vicarious experiences from their partners.

Moreover, couples deciding to quit jointly might also be high in dyadic efficacy, i.e., these couples were confident that they are able to achieve something as a team (Sterba et al., 2011). The co-development of both partner's self-efficacy might be partially explained by couples' dyadic efficacy and less so by one partner's mastery experience.

As opposed to previous research among heterosexual couples, no gender effects were found (Lüscher \& Scholz, 2016). That women are more likely to have an impact on men's smoking cessation than vice versa (Westmaas, Wild, \& Ferrence, 2002), could not be observed in our data. This is, however, in line with recent studies (e.g., Jackson et al., 2015).

\section{Strengths \& Limitations}

The reported studies share the strengths of using daily diaries and using the same measures to investigate rapid changes in mastery experiences and self-efficacy within smokers' quit attempts. This diary-approach had the advantage of high ecological validity as compared to studies conducted in the laboratory, allowed for the analyses of within-person 
changes instead of drawing conclusions from the between-person level, and shed light on the potential predictive order of cognitions and behaviour in the behaviour change process. It can, however, not be ruled out that faster changes in mastery experiences and self-efficacy (e.g., on an hourly basis, or cued by the environment) occurred that were not recorded due to one-day assessment intervals in both studies. Future studies should consider assessing data not only once but several times a day while keeping participant burden in mind. Also latest smartphone applications can prompt participants to report mastery experiences and selfefficacy context-based by use of geo-fencing, such as when they managed to stay abstinent in high-risk situations like bars (Naughton, 2017). A further limitation is that no objective measure of smoking abstinence was employed at the daily level, however smoking abstinence was biochemically verified with a CO test of expired air (West, Hajek, Stead, \& Stapleton, 2005) after the diary period. Self-reports of days with no mastery experience might therefore be biased in terms of underreporting.

In Study 2, partners' mastery experiences served as vicarious experiences for the respective individuals. Although the best way to operationalize vicarious experience in this study, this assumption is not without challenges. First, it is uncertain whether partners informed each other about their smoking status each day. From the literature of social control, it is known that hiding the smoking behaviour (i.e., the non-mastery experience) from a controlling partner is not uncommon (e.g., Ochsner et al., 2015; Scholz et al., 2013). Second, vicarious experiences work best, when the observer perceives immediate and positive consequences of the observed behaviour in the role model (or positive consequences of the non-performance of a behaviour in case of smoking; Bandura, 1977). Although it can be assumed that intimate partners, who decide on a joint quit attempt, inform each other about successes and failures as well as their thoughts and emotions about their experiences regularly, we cannot rule out that partners might report negative consequences of nonsmoking, too, endangering their role-model status for each other. 
Both studies had very strict inclusion criteria that restricted the samples' representativeness and the results may not generalize to the population of adult smokers. Future studies are advised to seek a more diverse sample, especially to include same-sex couples as far too few studies are being conducted on health behaviours other than HIV prevention in this population and first studies on same-sex couples show that their support mechanisms might work differently than in opposite-sex couples (Reczek, 2012; Reczek, Liu, \& Brown, 2014).

\section{Future research}

To disentangle positive from negative vicarious experiences, we suggest to not only measure each individual's behaviour and cognitive appraisal, but also try to assess the information partners share with each other at the end of the day. Jackson et al. (2015) concluded that smoking is much more dependent on the partner's behaviour - or rather on a partner's recent successful quit attempt - than for example physical activity or weight loss. Our analyses also confirm that smoking should be studied in the context of close social relationships. To uncover the social-cognitive mechanisms and unconscious effects behind these contagion effects, future research might have to go beyond self-efficacy theory and take a look at further possible working mechanisms. Jackson and colleagues (2015) for example assume that having a partner, who successfully quit, reduces the exposure to smoking-related cues and therefore eases the partner's path into abstinence. In addition to building partners' confidence in being able to succeed and reducing smoking related cues, intimate partners are also known for their continued attempts to influence their partners' health behaviours either directly or indirectly (Scholz et al., 2013; Westmaas et al., 2010). Future research might therefore benefit from taking partners' open and covert (invisible) social support into account, as both were found to play a role among smokers trying to quit (Lüscher \& Scholz, 2016; Lüscher et al., 2015; Scholz et al., 2016).

\section{Practical Implications}


First, the results of the current paper suggest that mastery experiences as well as selfefficacy are fluctuating during a smoking quit attempt. Although mastery experiences had a lagged effect on self-efficacy, this effect faded rapidly (after one day), which suggests that smokers trying to quit, would not benefit much from dated mastery experiences, but need new successes to hold up their challenged self-efficacy beliefs during a quit attempt. Secondly, it can be concluded that quitting smoking in close relationships operates under social influence. Even though the hypothesis that vicarious experiences affect intimate partners' self-efficacy could not be supported, there were nevertheless contagion effects of partners' self-efficacy and mastery experience on one another on a daily level. This highlights the importance of including both partners of dual-smoker couples in interventions, as treating only one might negatively impact intervention success (Jackson et al., 2015). This implication is especially important when interventions for specific populations are designed such as for pregnant women or patients recovering from cardiovascular events for whom a non-quitting partner would pose a constant risk for contagion of low self-efficacy beliefs and cues to lapse (Manchón Walsh et al., 2007).

Ethical approval: All procedures performed in studies involving human participants were in accordance with the ethical standards of the institutional and/or national research committee and with the 1964 Helsinki declaration and its later amendments or comparable ethical standards. 


\section{References}

Allison, P. D. (2005). Fixed Effects Regression Methods for Longitudinal Data Using SAS. Cary, NC: SAS Institute.

Baldwin, A. S., Rothman, A. J., Hertel, A. W., Linde, J. A., Jeffery, R. W., Finch, E. A., \& Lando, H. A. (2006). Specifying the determinants of the initiation and maintenance of behavior change: An examination of self-efficacy, satisfaction, and smoking cessation. Health Psychology, 25(5), 626-634. doi:10.1037/0278-6133.25.5.626

Bandura, A. (1977). Self-efficacy: Toward a unifying theory of behavioral change. Psychological Review, 84(2), 191-215. doi:10.1037/0033-295x.84.2.191

Bandura, A. (1995). Self-efficacy in changing societies. Cambridge: Cambridge University Press.

Bandura, A. (1997). Self-efficacy: the exercise of control. New York: Freeman.

DiClemente, C. C., Fairhurst, S. K., \& Piotrowski, N. A. (1995). Self-efficacy and addictive behaviors. In J. E. Maddux \& J. E. Maddux (Eds.), Self-efficacy, adaptation, and adjustment: Theory, research, and application. (pp. 109-141). New York, NY, US: Plenum Press.

Dijkstra, A., \& Vries, H. D. (2000). Self-efficacy expectations with regard to different tasks in smoking cessation. Psychology \& Health, 15(4), 501-511. doi:10.1080/08870440008402009

French, D. P. (2013). The role of self-efficacy in changing health-related behaviour: Cause, effect or spurious association? British Journal of Health Psychology, 18(2), 237-243. doi:10.1111/bjhp.12038

French, D. P., Olander, E., Chisholm, A., \& Mc Sharry, J. (2014). Which behaviour change techniques are most effective at increasing older adults' self-efficacy and physical activity behaviour? A systematic review. Annals of Behavioral Medicine, 48(2), 225234. doi:10.1007/s12160-014-9593-Z

Garcia, M. E., Schmitz, J. M., \& Doerfler, L. A. (1990). A fine-grained analysis of the role of self-efficacy in self-initiated attempts to quit smoking. Journal of Consulting and Clinical Psychology, 58(3), 317-322. doi:10.1037/0022-006X.58.3.317

Gmel, G., Kuendig, H., Notari, L., \& Gmel, C. (2015). Suchtmonitoring Schweiz - Konsum von Alkohol, Tabak und illegalen Drogen in der Schweiz im Jahr 2014 [Addiction monitoring in Switzerland - consumptions of alcohol, tabacco and drugs in Switzerland in 2014]. Lausanne, Schweiz: Sucht Schweiz.

Gmel, G., Kuendig, H., Notari, L., Gmel, C., \& Flury, R. (2013). Suchtmonitoring Schweiz Konsum von Tabak in der Schweiz im Jahr 2012 [Addiction monitoring in Switzerland - consumptions of alcohol, tabacco and drugs in Switzerland in 2012]. Lausanne, Schweiz: Sucht Schweiz.

Gwaltney, C. J., Bartolomei, R., Colby, S. M., \& Kahler, C. W. (2008). Ecological momentary assessment of adolescent smoking cessation: A feasibility study. Nicotine \& Tobacco Research, 10(7), 1185-1190. doi:10.1080/14622200802163118

Gwaltney, C. J., Metrik, J., Kahler, C. W., \& Shiffman, S. (2009). Self-efficacy and smoking cessation: A meta-analysis. Psychology of Addictive Behaviors, 23(1), 56-66. doi:10.1037/a0013529

Gwaltney, C. J., Shiffman, S., \& Sayette, M. A. (2005). Situational correlates of abstinence self-Efficacy. Journal of Abnormal Psychology, 114(4), 649-660. doi:10.1037/0021843X.114.4.649

Hughes, J. R., Keely, J., \& Naud, S. (2004). Shape of the relapse curve and long-term abstinence among untreated smokers. Addiction, 99(1), 29-38. doi:10.1111/j.13600443.2004.00540.x 
Jackson, S. E., Steptoe, A., \& Wardle, J. (2015). The influence of partner's behavior on health behavior change: the English Longitudinal Study of Ageing. JAMA Internal Medicine, 175(3), 385-392. doi:10.1001/jamainternmed.2014.7554

Kirchner, T. R., Shiffman, S., \& Wileyto, E. P. (2012). Relapse dynamics during smoking cessation: Recurrent abstinence violation effects and lapse-relapse progression. Journal of Abnormal Psychology, 121(1), 187-197. doi:10.1037/a0024451

Levy, D. A., \& Nail, P. R. (1993). Contagion: a theoretical and empirical review and reconceptualization. Genet Soc Gen Psychol Monogr, 119(2), 233-284.

Lüscher, J., \& Scholz, U. (2016). Does social support predict smoking abstinence in dualsmoker couples? Evidence from a dyadic approach. Anxiety, Stress, \& Coping, 1-9. doi:10.1080/10615806.2016.1270448

Lüscher, J., Stadler, G., Ochsner, S., Rackow, P., Knoll, N., Hornung, R., \& Scholz, U. (2015). Daily negative affect and smoking after a self- set quit attempt: The role of dyadic invisible social support in a daily diary study. British Journal of Health Psychology, 20(4), 708-723. doi:10.1111/bjhp.12135

Luszczynska, A., \& Schwarzer, R. (2015). Predicting health behaviours In M. Conner \& P. Norman (Eds.), Social-cognitive theory (3rd ed., pp. 225-251). UK, Maidenhead: McGraw Hill Open University Press.

Maddux, J. E. (2002). Self-efficacy: The power of believing you can. In C. R. Snyder \& S. J. Lopez (Eds.), Handbook of positive psychology. (pp. 277-287). New York, NY US: Oxford University Press.

Manchón Walsh, P., Carrillo, P., Flores, G., Masuet, C., Morchon, S., \& Ramon, J. M. (2007). Effects of partner smoking status and gender on long term abstinence rates of patients receiving smoking cessation treatment. Addictive Behaviors, 32(1), 128-136. doi:10.1016/j.addbeh.2006.03.027

Naughton, F. (2017). Delivering “Just-In-Time” Smoking Cessation Support Via Mobile Phones: Current Knowledge and Future Directions. Nicotine \& Tobacco Research, 19(3), 379-383. doi:10.1093/ntr/ntw143

Ochsner, S., Knoll, N., Stadler, G., Luszczynska, A., Hornung, R., \& Scholz, U. (2015). Interacting effects of receiving social control and social support during smoking cessation. Annals of Behavioral Medicine, 49(1), 141-146.

Palmer, D. H. (2006). Sources of Self-Efficacy in a Science Methods Course for Primary Teacher Education Students. Research in Science Education, 36(4), 337-353. doi:10.1007/s11165-005-9007-0

Reczek, C. (2012). The promotion of unhealthy habits in gay, lesbian, and straight intimate partnerships. Social Science \& Medicine (1982), 75(6), 1114-1121. doi:10.1016/j.socscimed.2012.04.019

Reczek, C., Liu, H., \& Brown, D. (2014). Cigarette Smoking in Same-Sex and Different-Sex Unions: The Role of Socioeconomic and Psychological Factors. Population Research \& Policy Review, 33(4), 527-551. doi:10.1007/s11113-013-9297-2

Roberts, V., Dale, L. P., Dorey, E., Bullen, C., \& Maddison, R. (2016). An exercise programme for smoking cessation: Perceptions of the Fit2Quit trial intervention. Journal of Smoking Cessation, 11(3), 135-142. doi:10.1017/jsc.2014.16

Scholz, U., Berli, C., Goldammer, P., Lüscher, J., Hornung, R., \& Knoll, N. (2013). Social control and smoking: Examining the moderating effects of different dimensions of relationship quality. Families, Systems, \& Health, 31(4), 354. doi:10.1037/a0033063

Scholz, U., Nagy, G., Gohner, W., Luszczynska, A., \& Kliegel, M. (2009). Changes in selfregulatory cognitions as predictors of changes in smoking and nutrition behaviour. Psychology \& Health, 24(5), 545-561. doi:10.1080/08870440801902519

Scholz, U., Stadler, G., Ochsner, S., Rackow, P., Hornung, R., \& Knoll, N. (2016). Examining the relationship between daily changes in support and smoking around a 
self-set quit date. Health Psychology, 35(5), 514-517. doi:10.1037/hea0000286

(10.1037/hea0000286.supp)

Schwarzer, R. (2008). Modeling health behavior change: how to predict and modify the adoption and maintenance of health behaviors. Applied Psychology, 57(1), 1-29. doi:10.1111/j.1464-0597.2007.00325.x

Shiffman, S., Balabanis, M. H., Paty, J. A., Engberg, J., Gwaltney, C. J., Liu, K. S., . . . Paton, S. M. (2000). Dynamic effects of self-efficacy on smoking lapse and relapse. Health Psychology, 19(4), 315-323. doi:10.1037/0278-6133.19.4.315

Stadler, G., Snyder, K. A., Horn, A. B., Shrout, P. E., \& Bolger, N. P. (2012). Close relationships and health in daily life: a review and empirical data on intimacy and somatic symptoms. Psychosomatic Medicine, 74(4), 398-409. doi:10.1097/PSY.0b013e31825473b8

Sterba, K. R., Rabius, V., Carpenter, M. J., Villars, P., Wiatrek, D., \& McAlister, A. (2011). Dyadic efficacy for smoking cessation: preliminary assessment of a new instrument. Nicotine \& Tobacco Research, 13(3), 194-201. doi:10.1093/ntr/ntq236

Van Zundert, R. M. P., Engels, R. C. M. E., \& Kuntsche, E. (2011). Contextual correlates of adolescents' self-efficacy after smoking cessation. Psychology of Addictive Behaviors, 25(2), 301-311. doi:10.1037/a0023629

Warner, L. M., Schüz, B., Wolff, J. K., Parschau, L., Wurm, S., \& Schwarzer, R. (2014). Sources of self-efficacy for physical activity. Health Psychology, 33(11), 1298-1308. doi:10.1037/hea0000085

West, R., Hajek, P., Stead, L., \& Stapleton, J. (2005). Outcome criteria in smoking cessation trials: Proposal for a common standard. Addiction, 100, 299-303. doi:10.1111/j.13600443.2005.00995.x

Westmaas, J. L., Bontemps-Jones, J., \& Bauer, J. E. (2010). Social support in smoking cessation: Reconciling theory and evidence. Nicotine \& Tobacco Research, 12(7), 695-707. doi:10.1093/ntr/ntq077

Westmaas, J. L., Wild, T. C., \& Ferrence, R. (2002). Effects of gender in social control of smoking cessation. Health Psychology, 21(4), 368-376. doi:10.1037/02786133.21.4.368

World Health Organization. (1998). Guidelines for controlling and monitoring the tobacco epidemic. Geneva: World Health Organization.

World Health Organization. (2011). WHO Report on the Global Tobacco Epidemic, 2011. Geneva: World Health Organization. 
Table 1

Multilevel model results of Study 1 and Study 2 predicting concurrent change in self-efficacy

\begin{tabular}{|c|c|c|c|c|c|}
\hline & \multirow[t]{3}{*}{ Study 1} & \multicolumn{4}{|c|}{ Study 2} \\
\hline & & \multicolumn{2}{|c|}{ Models without partner effects } & \multicolumn{2}{|c|}{ Models with partner effects } \\
\hline & & Women & Men & Women & Men \\
\hline & $b(S E)$ & $b(S E)$ & $b(S E)$ & $b(S E)$ & $b(S E)$ \\
\hline \multicolumn{6}{|l|}{ Fixed Effects } \\
\hline Intercept & $-0.032(.014)^{*}$ & $-0.014(.014)$ & $-0.039(.031)$ & $-0.033(.056)$ & $0.003(.029)$ \\
\hline Time & $0.001(.001)$ & $0.001(.001)$ & $0.003(.003)$ & $0.002(.002)$ & $-0.001(.003)$ \\
\hline Individuals' prior change in SEff & $-0.219(.034)^{* * *}$ & $-0.156(.045)^{* *}$ & $-0.590(.042)^{* * *}$ & $-0.299(.028) * * *$ & $-0.569(.024) * * *$ \\
\hline Individuals' prior change in MA & $0.168(.057)^{* *}$ & $0.178(.093)$ & $0.146(.108)$ & $0.381(.085)^{* * *}$ & $0.256(.116)^{*}$ \\
\hline Individuals' concurrent change in MA & $0.362(.076)^{* * *}$ & $0.312(.073) * * *$ & $0.214(.091)^{*}$ & $0.294(.083) * * *$ & $0.288(.095)^{* *}$ \\
\hline Partner's prior change in SEff & - & - & - & $0.118(.024)^{* * *}$ & $0.137(.035) * * *$ \\
\hline Partner's concurrent change in SEff & - & - & - & $0.107(.023)^{* * *}$ & $0.143(.034) * * *$ \\
\hline Partner's prior change in MA & - & - & - & $0.019(.078)$ & $-0.158(.109)$ \\
\hline Partner's concurrent change in MA & - & - & - & $0.108(.081)$ & $-0.090(.109)$ \\
\hline Autocorrelation & see (a) & see (b) & see $(c)$ & see $(d)$ & see (e) \\
\hline
\end{tabular}

Note. $* p<.05, * * p<.01, * * * p<.001$; Intercept at Day 13, which was two days after the quit date; time was centered at Day 13; $b=$ unstandardized regression coefficients; SE = Standard Error, MA = Mastery Experiences, SEff = Self-efficacy; estimates for random effects, correlation matrices for estimates of random effects and residual covariance structures can be found in the online supplemental material (Tables 3 to 32).

a) The heterogeneous Toeplitz variance covariance matrix showed an autocorrelation between adjacent days of -.32 in the first band that decreased rapidly, to -.14 in the second band, fluctuating around 0 for subsequent bands that are three days and more apart (see Appendix Table 4). 
b) The heterogeneous Toeplitz variance covariance matrix showed an autocorrelation between adjacent days of -.32 in the first band that decreased rapidly, to -.13 in the second band, fluctuating around 0 for subsequent bands that are three days and more apart (see Appendix Table 7).

c) The heterogeneous Toeplitz variance covariance matrix showed an autocorrelation between adjacent days of -.01 in the first band that increased to -.39 in the second band, but fluctuated around 0 for subsequent bands that are three days and more apart (see Appendix Table 10).

d) The heterogeneous Toeplitz variance covariance matrix showed an autocorrelation between adjacent days of -.27 in the first band that decreased rapidly, to -.9 in the second band, fluctuating around 0 for subsequent bands that are three days and more apart (see Appendix Table 13).

e) The heterogeneous Toeplitz variance covariance matrix showed an autocorrelation between adjacent days of -.10 in the first band that increased to -.37 in the second band, but fluctuated around 0 for subsequent bands that are three days and more apart (see Appendix Table 16). 
Table 2

Multilevel model results of Study 1 and Study 2 predicting concurrent change in mastery experiences

\begin{tabular}{|c|c|c|c|c|c|}
\hline & \multirow[t]{3}{*}{ Study 1} & \multicolumn{4}{|c|}{ Study 2} \\
\hline & & \multicolumn{2}{|c|}{ Models without partner effects } & \multicolumn{2}{|c|}{ Models with partner effects } \\
\hline & & Women & Men & Women & Men \\
\hline & $b(S E)$ & $b(S E)$ & $b(S E)$ & $b(S E)$ & $b(S E)$ \\
\hline \multicolumn{6}{|l|}{ Fixed Effects } \\
\hline Intercept & $0.002(.004)$ & $0.004(.007)$ & $0.004(.005)$ & $0.013(.011)$ & $0.006(.012)$ \\
\hline Time & $-0.001(.001)$ & $-0.001(.001)$ & $-0.001(.001)$ & $-0.002(.001)$ & $-0.001(.001)$ \\
\hline Individuals' prior change in MA & $-0.239(.054)^{* * *}$ & $-0.425(.025) * * *$ & $-0.253(.054)^{* * *}$ & $-0.237(.061)^{* *}$ & $-0.271(.051)^{* * *}$ \\
\hline Individuals' prior change in SEff & $0.062(.016)^{* * *}$ & $0.032(.009)^{* *}$ & $0.025(.012)^{*}$ & $0.031(.014)^{*}$ & $0.014(.011)$ \\
\hline Individuals' concurrent change in SEff & $0.074(.016)^{* * *}$ & $0.027(.009)^{* *}$ & $0.040(.015)^{*}$ & $0.042(.017)^{*}$ & $0.014(.009)$ \\
\hline Partner's prior change in MA & - & - & - & $0.085(.047)$ & $0.076(.051)$ \\
\hline Partner's concurrent change in MA & - & - & - & $0.204(.059)^{* *}$ & $0.277(.075)^{* *}$ \\
\hline Partner's prior change in SEff & - & - & - & $0.003(.009)$ & $0.025(.017)$ \\
\hline Partner's concurrent change in SEff & - & - & - & $-0.005(.011)$ & $0.012(.015)$ \\
\hline Autocorrelation & see (f) & see $(g)$ & see (h) & see (i) & see $(j)$ \\
\hline
\end{tabular}

Note. $* p<.05, * * p<.01, * * * p<.001$; Intercept at Day 13, which was two days after the quit date; time was centered at Day 13; $b=$ unstandardized regression coefficients; $\mathrm{SE}=$ standard error, $\mathrm{MA}=$ mastery experiences, $\mathrm{SEff}$ = self-efficacy; estimates for random effects, correlation matrices for estimates of random effects and residual covariance structures can be found in the online supplemental material (Tables 3 to 32).

f) The Toeplitz variance covariance matrix showed an autocorrelation between adjacent days of 0.07 in the first band that decreased to -.19 in the second band and -.32 in the third band before fluctuating around 0 for subsequent bands that are three days and more apart (see Appendix Table 19). 
g) The Toeplitz variance covariance matrix showed an autocorrelation between adjacent days of 0.07 in the first band that decreased to -.12 in the second band and -.29 in the third band before fluctuating around 0 for subsequent bands that are three days and more apart (see Appendix Table 22).

h) The Toeplitz variance covariance matrix showed an autocorrelation between adjacent days of 0.08 in the first band that decreased to -.32 in the second band and -.20 in the third band before fluctuating around 0 for subsequent bands that are three days and more apart (see Appendix Table 25).

i) The AR1 variance covariance matrix showed an autocorrelation between adjacent days of 0.04 that decreased to -.24 for subsequent days (see Appendix Table 28).

j) The AR1 variance covariance matrix showed an autocorrelation between adjacent days of 0.06 that decreased to -.30 for subsequent days (see Appendix Table 31). 